\title{
Effect of Varying Hot Surface Temperature on Ignition Delay Characteristics for Different Fuel Sprays
}

\author{
Tushar Gupta, M. Emran Khan
}

\begin{abstract}
An experimental work is performed in a constant volume combustion chamber to study the effect of varying hot surface temperature on ignition delay characteristics for different fuel sprays (Hollow cone spray and Solid cone spray). For ejecting the sprays pintle and single hole nozzles were used. In this experimental work hot surface temperature (HST) varied from $350^{\circ} \mathrm{C}$ to $550^{\circ} \mathrm{C}$, air pressure inside the cylinder varied from 10 to 25 bar while fuel injection pressures varied from 10 to 20 MPa. Optical method is used for detecting the flame appearance while a digital Oscilloscope is used to measure ID of sprays by recording the gap between injection event and the event of appearance of flame. During the work it is found that ID is strong function of HST rather than other operating parameters. It is also found that on increasing HST, for both sprays ignition delay is decreasing at every injection pressures.
\end{abstract}

Keywords : Spray, Pintle nozzle, Single hole nozzle, Cetane number, ID, HST.

\section{INTRODUCTION}

Primary source of power for the heavy duty vehicles like large trucks, buses and mining equipments are diesel engines [1]. So they are commonly used in transportation. Along with environment pollution increasing diesel price is also another problem [2]. The popularity of diesel engines is mainly due to low fuel consumption. However, the major air pollutants are also emitted from the Diesel engines. To achieve all these standards and norms, the engineer has to develop new processes and techniques used for diesel engines combustion. Diesel engines combustion nature is mainly determined by the quality of fuel spray its mixing and distribution inside the combustion chamber. In-cylinder conditions like nozzle design and geometry, air motion, temperature, density and injection pressure mainly governed the breakup and distribution of the spray [3].

Manuscript published on November 30, 2019

* Correspondence Author

Tushar Gupta*, Research Scholar, Mechanical Engg Deptt., Jamia Millia Islamia, Delhi, India

Address: 99T, Premier Nagar, Aligarh-20201, U.P., India

Email: tgupta1987@gmail.com

M. Emran Khan,Professor, Mechanical Engg Deptt., Jamia Millia Islamia, Delhi, India

Address: 633/9, R-4, Lane-9, Zakir Nagar New Delhi-110025, India

Email: emran_jmi@yahoo.com

(C) The Authors. Published by Blue Eyes Intelligence Engineering and Sciences Publication (BEIESP). This is an open access article under the CC-BY-NC-ND license (http://creativecommons.org/licenses/by-nc$\underline{\mathrm{nd} / 4.0 /)}$
In the today's world, Different countries adopted different emissions norms to check the air pollution. Presently Bharat Stage IV norms are adopted in India. Soon India will adopt Bharat Stage VI norms (in year2020) by taking euro norms VI as its reference. Researchers are trying to find ways to reduce pollutants emitted from engines by studying diesel combustion processes, various alternative fuels and different geometry of nozzle. Less emissions, fuel efficiency and cost effectiveness can be optimized by getting proper combustion inside the engine. This led to advancement of new combustions systems. In this study, fabrication and experiment is carried out to investigate the effect of different geometry of fuel spray (Pintle nozzle and Single hole nozzle) on diesel combustion characteristic.

A. Diesel engine combustion: The combustion process, emission characteristics and spray pattern inside the diesel engine (CI Engine) can be understood by the following diagrams:

\section{Four Stages of Combustion in $\mathrm{Cl}$ Engines}

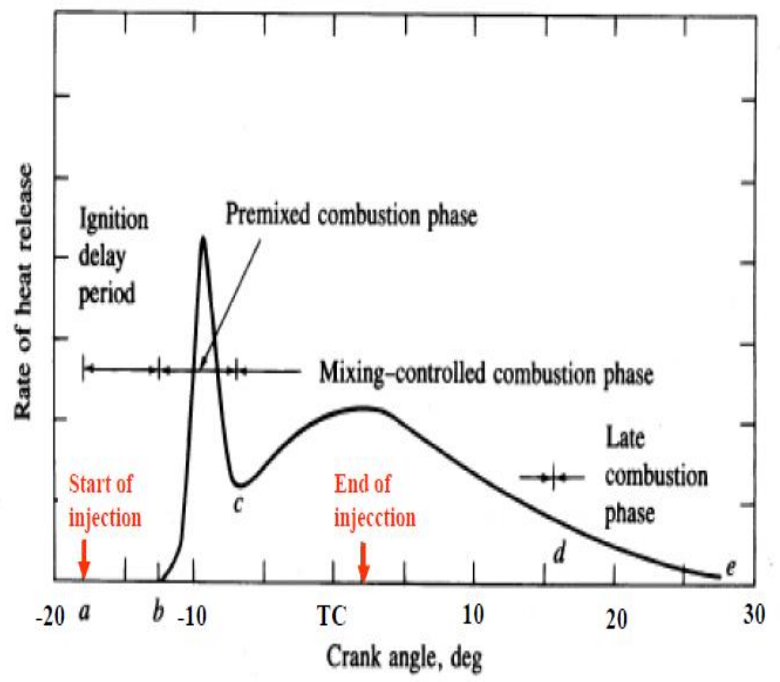

Figure 1: ROHR Curve for Diesel Engine [4]

The four stages of the entire combustion process in CI engine are categorizes as Ignition delay (ab), Premixed combustion phase (bc), Mixing controlled combustion phase (cd), Late combustion phase (de). The combustion steps, taking place in DI-Diesel engines are briefly given in Fig 2. 


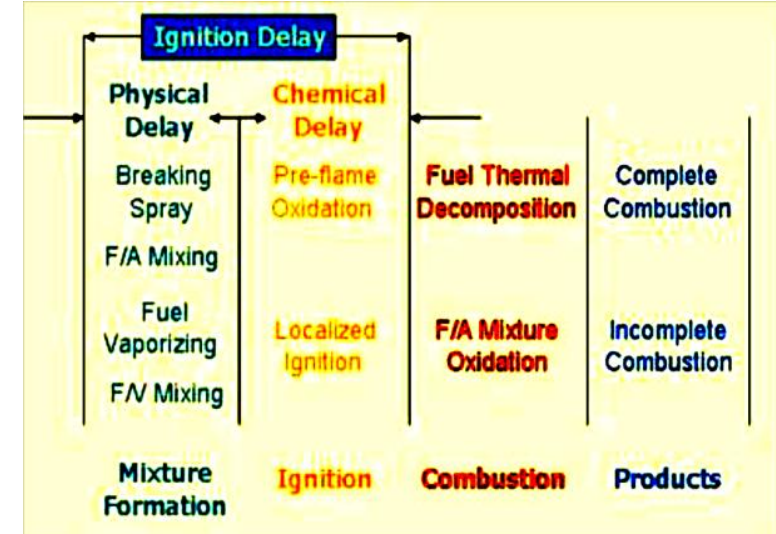

Figure 2: Combustion steps in DI diesel engine [4]

\section{B. Ignition Delay}

In diesel engines, ignition delay of the fuel is the time lag between beginnings of fuel injection to the initiation of combustion [4].

It is subdivided into two parts:

- $\quad$ Physical delay

- Chemical delay

Physical delay involves atomization, vaporization and mixing of fuel with air while chemical delay involves preflame reactions until ignition occurs [5].

\section{Spray pattern}

The two types of basic spray cone patterns (Hollow cone and solid cone) were used in this work. Each has certain advantages depending on its use. Pintle nozzle is used for getting hollow cone spray while Single hole nozzle is used for getting solid cone spray in this work. Hollow cone spray is a spray with very little or no fuel in the center of the spray while more concentration is at the outer periphery of spray and in the solid cone spray uniform distribution of fuel droplets is present everywhere in spray.

By reducing ignition delay, NOx emissions can be reduced as larger ignition delay generate higher peak of ROHR [6].

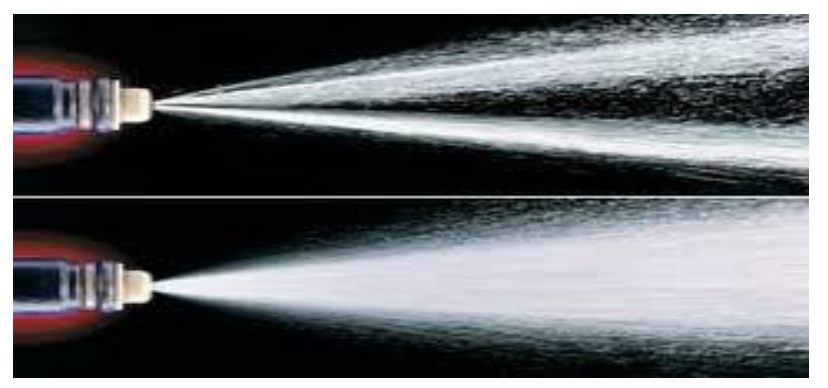

Figure 3: hollow cone spray and solid spray

Many experiments have been done to know the spray behavior and emissions librated during combustion. Some of them are as follows:

Ignition delay decreased due to the better mixing at higher injection pressures [7]. Effect of nozzle size was very important factor to affect the spray characteristics [8]. To reduce the emissions very high injection pressure and smaller diameter nozzles can be used [9]. Spray-guided combustion is very nice strategy to reduce fuel consumption

and $\mathrm{CO} 2$ emissions in S.I. engines [10]. Between diesel and biodiesels, to know the difference of spray flame characteristics combination of non evaporating spray and spray combustion measurements can be used [11]. At higher injection pressure, although emissions of $\mathrm{CO}$ and UHC are reduced but emissions of $\mathrm{NO} x$ and $\mathrm{CO} 2$ are increased [12]. Split injection reduces soot rapidly instead of single injection [13]. By improving airflow inside the engine intake, efficiency of engine can be increased. [14]. Ignition delay is a decreasing function of low and moderate injection pressure [15]. Controlling the fuel injection timing, soot formation can be reduced [16]. For diesel and gasoline blended diesel, ignition delay is a strong function of hot surface temperature [17]. Higher fuel injection rate and wider fuel spray distribution can be used to reduced fuel consumption and PM emissions [18].

\section{EXPERIMENTAL SETUP AND ITS COMPONENTS}

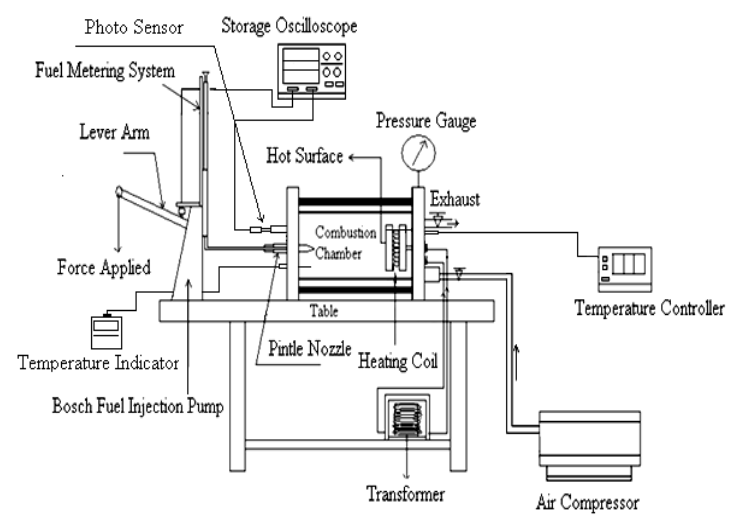

Figure 4: Block Diagram for the Experimental Setup

\section{Various Components of Experimental Set Up}

1. Bosch Fuel Injection Pump

2. Pump Plate:

3. Striking Pin

4. Rocker and Lever Arm

5. Fuel Metering

6. Piezo-electric Sensor

7. Photo Sensor

8. Injection Nozzle

9. Combustion chamber

10. Digital Oscilloscope

11. Temperature-Controller

12. Air Compressor

13. Temperature Indicator

\section{RESULT AND DISCUSSION}



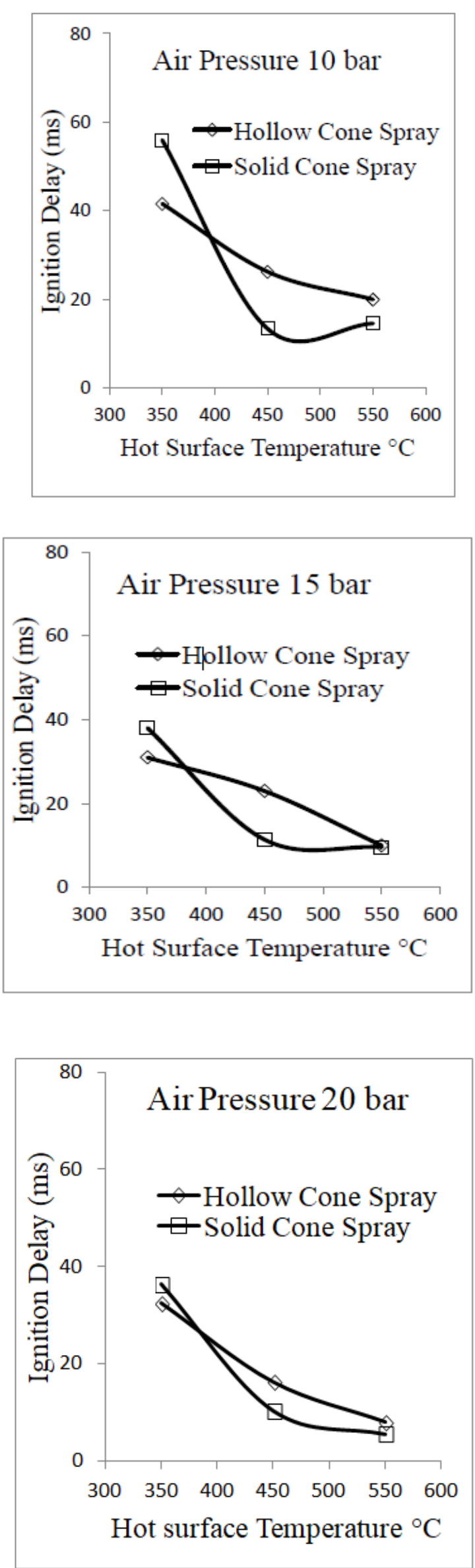

Retrieval Number: C6599098319/2019@BEIESP

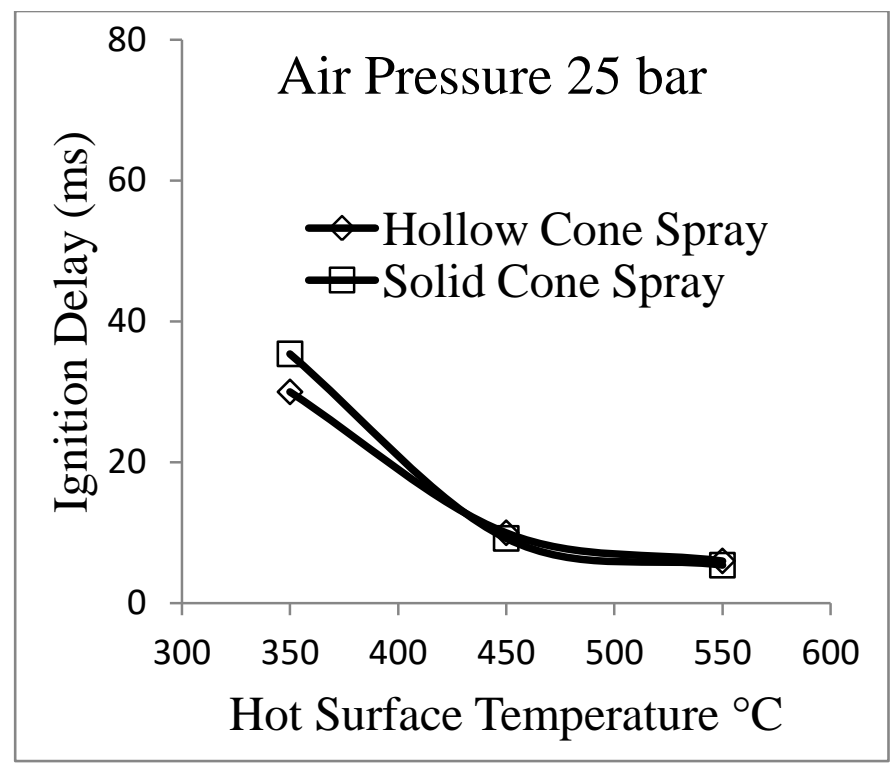

Figure 5: Effect of Variation of Hot Surface Temperature on Ignition Delay Characteristic of fuel Sprays for Injection Pressure 10 MPa at Different Air Pressure.

From the above figure it is clear that for all air pressures, value of ignition delay is always more for solid cone spray than hollow cone spary at 350C while the pattern is reversed at 450C. At 550C there is not so much variation in the value of ignition delay. It means at $350 \mathrm{C}$ hollow cone spray gives better result while at 450C solid cone spray gives better results and at 550C both sprays are showing same performance.

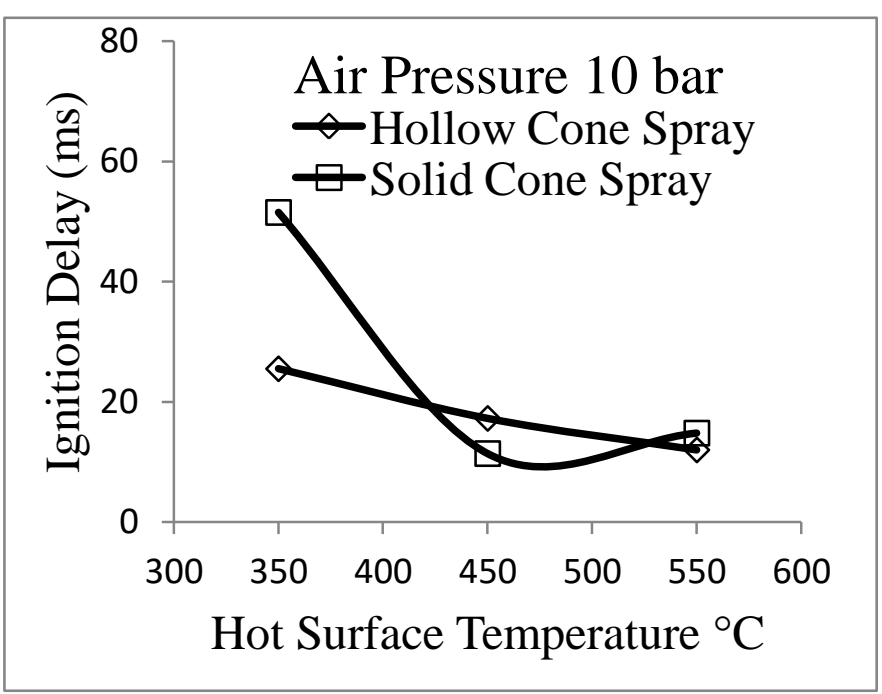

Published By:

Blue Eyes Intelligence Engineering 

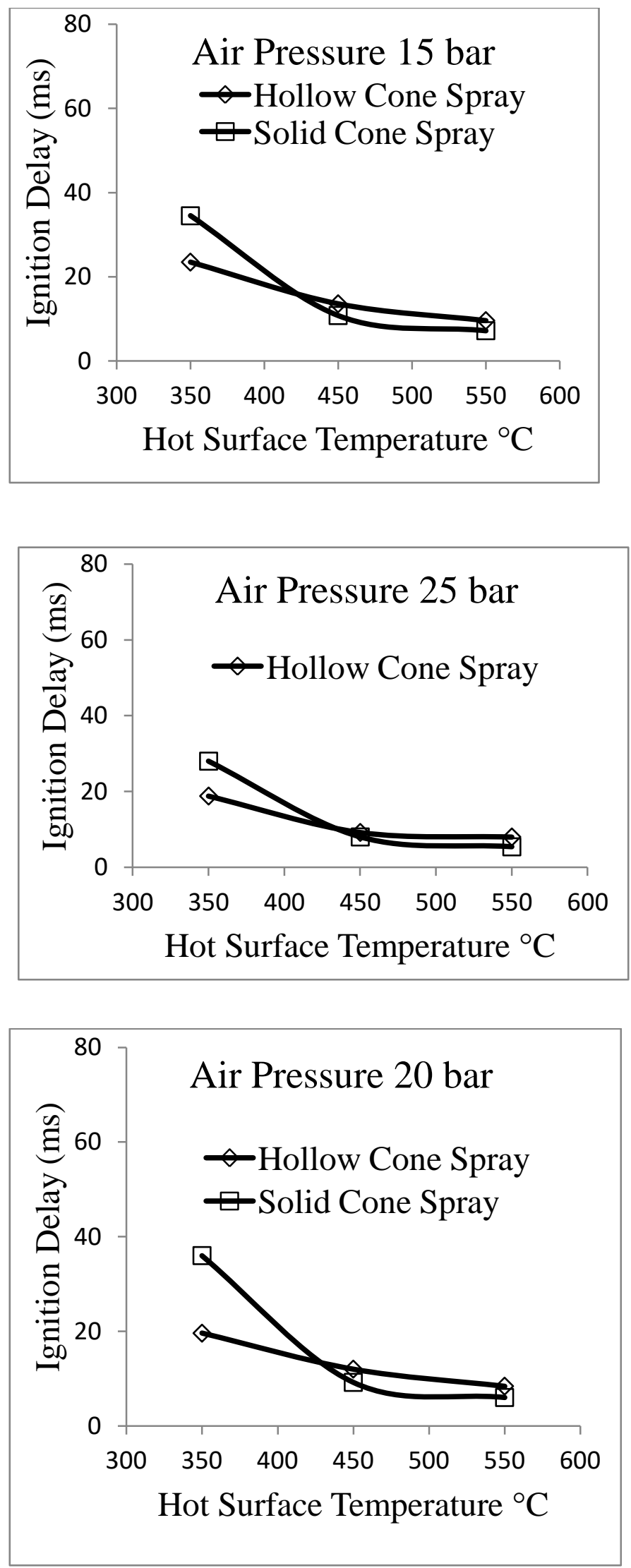

Figure 6: Effect of Variation of Hot Surface Temperature on Ignition Delay Characteristic of fuel Sprays for Injection Pressure $15 \mathrm{MPa}$ at Different Air Pressure.

From the above figure it is clear that for all air pressures, value of ignition delay is always more for solid cone spray than hollow cone spary at 350C.Although the value of ignition delay is lower for solid cone spray than hollow cone spray at $450 \mathrm{C}$ but the variation in values is very less.

At 550C there is not so much variation in the value of ignition delay for both types of sprays. It means that at 350 $\mathrm{C}$ hollow cone spray gives better result while at 450C solid cone spray gives better results and at 550C both sprays are showing same performance

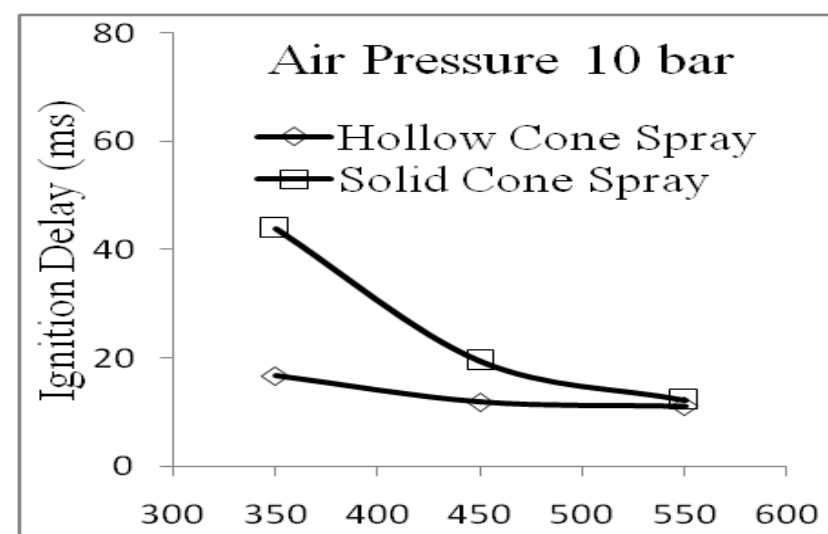

Hot Surface Temperature ${ }^{\circ} \mathrm{C}$
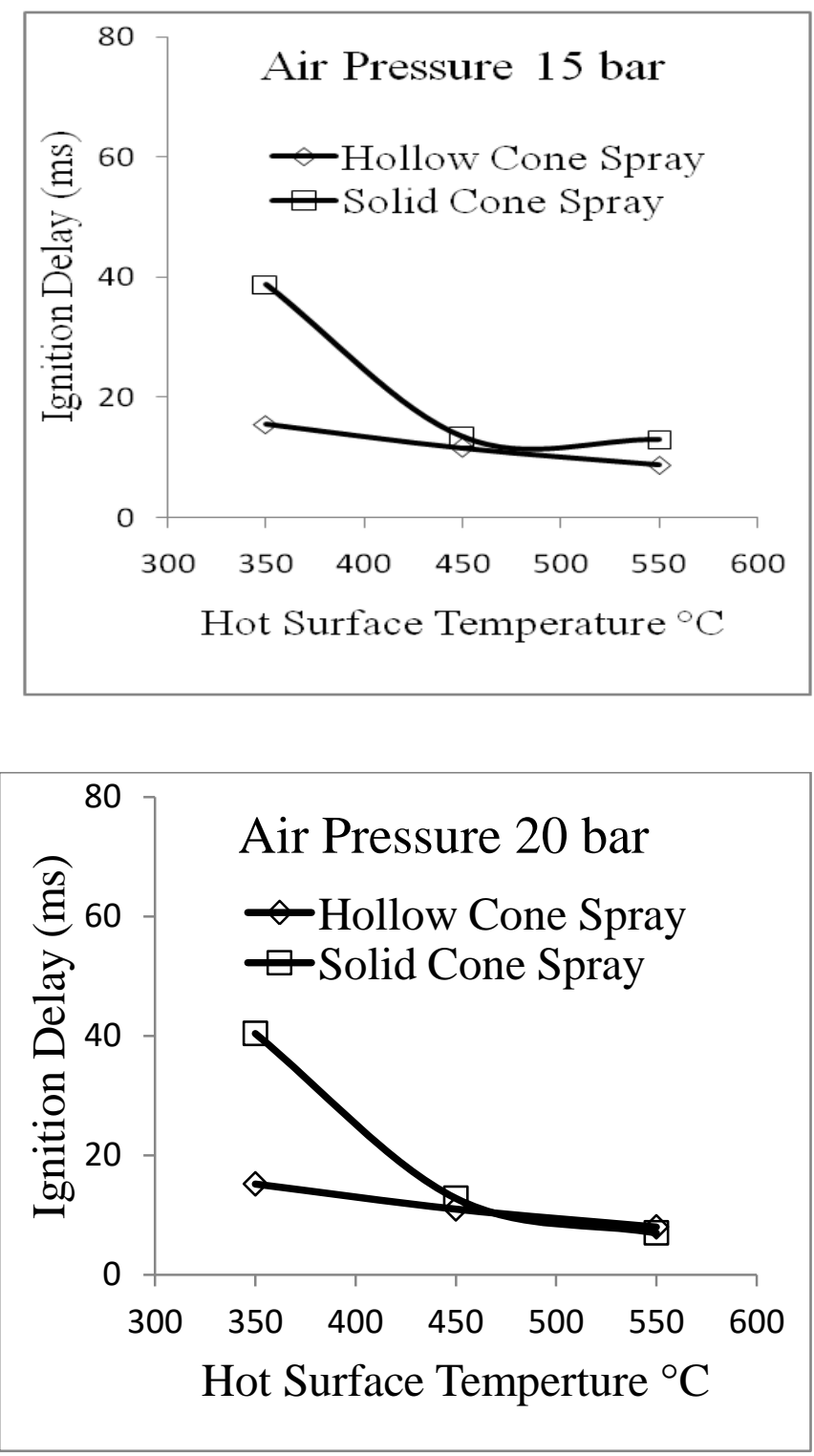

Published By:

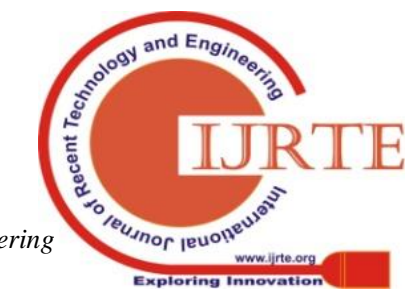




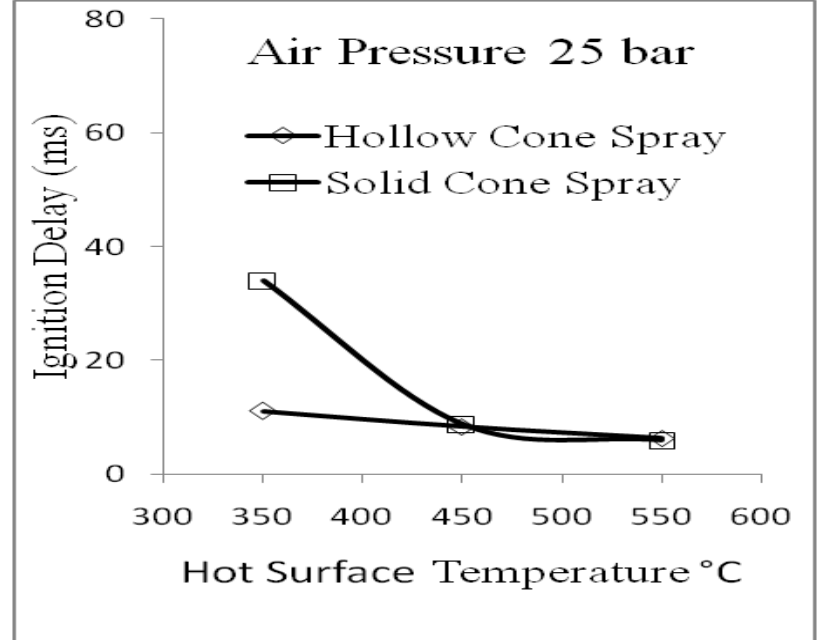

\section{Figure 7: Effect of Variation of Hot Surface Temperature on Ignition Delay Characteristic of fuel Sprays for Injection Pressure 20 MPa at Different Air Pressure.}

From the above figure it is clear that for all air pressures, value of ignition delay is always more for solid cone spray than hollow cone spary at 350C. At 450C and 550C the value of ignition delay is very close to each other for both types of sprays. It means that at $350 \mathrm{C}$ hollow cone spray gives better result while at 450 and 550C both sprays give almost same results.

\section{CONCLUSION}

1 Although air pressure, injection pressure and HST all are responsible for variation in ID but HST is more strongly affect the ID compared to other parameters. However at high temperatures the strong dependency is diluted.

2 On increasing the hot surface temperature, ignition delay is decreasing for both types of spray but this decrement is faster for solid cone spray than the hollow cone spray

3 At $350^{\circ} \mathrm{C}$, ID is higher for Solid Cone Spray than the Hollow Cone Spray for any Injection Pressure and Air Pressure. So pintle nozzle is recommended at this temperature.

4 At $450^{\circ} \mathrm{C}$, ID is lower for Solid Cone Spray than the Hollow Cone Spray for 100 bar and 150 bar Injection Pressure while at 200 bar Injection Pressure ID is almost same for both on all Air Pressure. So single hole nozzle is recommended at this temperature.

5 At $550^{\circ} \mathrm{C}$, ID for both types of Sprays is almost same at any Injection Pressure and Air Pressure. So we can use any type of nozzle at this temperature.

6 At lower Air Pressure and HST the variation in ID is more between Solid Cone Spray and Hollow Cone Spray while at higher values of Air Pressure and HST the variation is very much less.

7 ID of diesel fuel is decreasing by increasing the Injection Pressure.

\section{REFERENCES}

1. Kannan K. and Udayakumar M., "Experimental study of the effect of fuel injection pressure on diesel engine performance and emission", ARPN Journal of Engineering and Applied Sciences, Vol. 5, No. 5, May 2010.
2. Yusmady Bin M.A., "Diesel and Bio- diesel fuel deposits on a hot wall surface", PhD Thesis, Department of mechanical system engineering, Gunma University, Japan, August 2009.

3. Crua C., "Combustion Processes in C.I. Engines", PhD Thesis, School of Engineering, University of Brightoin collaboration with Ricardo Consulting Engineers, December 2002.

4. Heywood, J.B., "Internal Combustion Engines", Second Edition McGraw Hill International, New York, 1988

5. Prakash V., "Measurement of the ignition delay of oxygenated fuels blend sprays at high pressure", M. Tech. Thesis, Department of Mechanical Engineering , Z H College of Engineering \& Technology, Aligarh Muslim University, Aligarh, India, May 2011.

6. Wolfer, H.H., "Ignition Lag in Diesel Engines" VDI-Forschungsheft Library No.358, UDC 621-436.047, 1959.

7. KutiO. A. et al, "Effect of Injection Pressure on Ignition, Flame Development and Soot Formation Processes of Biodiesel Fuel Spray", SAE International Journal of Fuels and Lubricantsvol. 3 no. 2 10571070, December 2010.

8. Essam M. EL-Hannouny and Patrick V. Farrell, "Effect of Injection Parameters and Injection System on Spray Characteristics for HSDI Diesel Engines", Engine Research Center University of WisconsinMadison, WI 53706, July 2003.

9. Wang X. et al, "Effects of ultra-high injection pressure and micro-hole nozzle on flame structure and soot formation of impinging diesel spray", Applied Energy 88, November 2010

10. Buri S. et al, "Effects of increased injection pressures of up to $1000 \mathrm{bar}$ - opportunities in stratified operation in a direct-injection sparkignition engine", International Journal of Engine Research 473, September 2010.

11. Wang X. et al, "Effect of injection pressure on flame and soot characteristics of the biodiesel fuel spray", Taylor and Francis Group, March 2010.

12. Canakci M. et al, "Effect of Injection Pressure on the Combustion, Performance, and Emission Characteristics of a Diesel Engine Fueled with Methanol-blended Diesel Fuel”, Energy \& Fuels, Vol. 23, April 2009.

13. Nishioka Y., Tomoda H., Nishida K., Ogata Y., Kishorkumar G. et al "Combustion Characteristics of Diesel Spray with Temporally-Splitting High-Pressure Injection" SAE 2015 small Engine Technolologies Conference \& Exhibition, Technical Paper 2015-32-0825, November 2015.

14. Soares, S. and Leite, A., "Evaluation of the Influence of the Ducts of a Cylinder Head of Diesel Engine," SAE Technical Paper 2016-36-0382, 2016, doi:10.4271/2016-36-0382

15. Rehman S. "Sensors Based Measurement Techniques of Fuel Injection and Ignition Characteristics of Diesel Sprays in DI Combustion System", AEJ - Alexandria Engineering Journal 55(3), May 2016.

16. Pal P., Probst D., et al "Numerical Investigation of a Gasoline-Like Fuel in a Heavy-Duty Compression Ignition Engine Using Global Sensitivity Analysis" SAE world congress Experience, Journal Article 2017-01-0578, March 2017.

17. Rehman S., Zaidi K. "Experimental Study of Hot Surface Temperature Effect on Diesel and Blended Diesel Exhaust Emissions", International Conference on Environment and Energy, At Hyderabad, December 2014

18. Kang S, Cho W et al "Influence of the Injector Geometry at $250 \mathrm{MPa}$ Injection in a Light-Duty Diesel Engine" SAE world congress Experience, Technical Paper 2017-01-0693, March 2017.

\section{AUTHORS FROFILE}

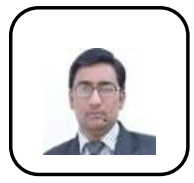

Tushar Gupta, is an eminent research scholar in JamiaMilliaIslamia, Delhi, India. He has been worked as assistant professor in G.LA. University (India), Galgotias University (India) ,Sharda group of Institutions (India) in past few years. He has been completed his graduation and post-graduation from A.M.U. (India).

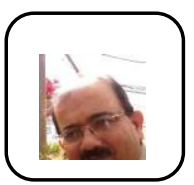

Professor M. Emran Khan, is Head of the department of Mechanical Engineering in JamiaMillliaIslamia, Delhi, India. He has been published so many research papers in reputed international journals and no. of books and book chapters in reputed publishers. He has teaching and research experience of 34 years. He is a member of NBA, planning commission of india and many selection committees. 